\title{
Postoperative abdominal adhesions and their prevention in gynaecological surgery. Expert consensus position. Part 2 - steps to reduce adhesions
}

\author{
Rudy Leon DeWilde • Geoffrey Trew • \\ On behalf of the Expert Adhesions Working Party \\ of the European Society of Gynaecological \\ Endoscopy (ESGE)
}

Received: 12 July 2007 / Accepted: 12 July 2007 / Published online: 10 August 2007

(C) Springer-Verlag 2007

\begin{abstract}
This consensus position represents the collective views of 35 gynaecologists with a recognised interest in adhesions. The first part of the position was presented in the previous issue of Gynecological Surgery and reviewed the published literature on the extent of the problem of adhesions. In this part, the opportunities to reduce their incidence are considered. Collective proposals on the actions that European gynaecologists should take to avoid causing adhesions are provided. Importantly, in this part, the need to now inform patients of the risks associated with adhesion-related complications during the consent process is discussed. With evidence increasing to support the efficacy of adhesion-reduction agents to complement good surgical practice, all surgeons should act now to reduce adhesions and fulfil their duty of care to patients.
\end{abstract}

Keywords Adhesions · Adhesiolysis · Guidelines · Gynaecology $\cdot$ Surgery

\footnotetext{
R. L. DeWilde $(\bowtie)$

Department OBGYN, Pius-Hospital,

Oldenburg, Germany

e-mail: rudy-leon.dewilde@pius-hospital.de

G. Trew

Reproductive Medicine and Surgery,

Hammersmith and Queen Charlotte's Hospital,

London, UK

e-mail: g.trew@ic.ac.uk

G. Trew

Imperial College, University of London,

London, UK
}

\section{Introduction}

Adhesions are the most frequent complication of abdominal surgery and may represent one of the greatest unresolved medical problems in medicine today [1], yet, many surgeons are still not aware of the extent of the problem and its serious consequences.

Recent epidemiological data have demonstrated that, despite advances in surgical techniques in recent years, the burden of adhesion-related complications has not changed $[2,3]$. While laparoscopic procedures are commonly believed to be less adhesiogenic and cause fewer de novo adhesions to form compared to open surgery $[4,5]$, for many procedures, the comparative risk of adhesion-related complications following open and laparoscopic gynaecological surgery is similar [3].

Developments in adhesion-reduction strategies and new agents do, however, now offer a realistic possibility of reducing the risk of adhesions forming and, thus, may improve the outcomes for patients and the associated onward burden. The importance of providing clear recommendations on adhesions and their prevention following gynaecological surgery is very apparent.

The paper details the second part of the project undertaken by the Expert Adhesions Working Party of the European Society of Gynaecological Endoscopy (ESGE).

The first paper published in the previous issue of Gynecological Surgery provided an overview of the published literature on the extent of the problem of adhesions and, in this paper, the opportunities to reduce it are presented. A consensus of opinion on the actions that European gynaecologists should now take is provided. These proposals are collective opinions and should not be used for performance measures or competency purposes. 
Together, these two papers provide a collective consensus position which it is hoped will raise the level of awareness and the understanding of adhesions, and the associated healthcare burden and costs, thereby, encouraging heightened discussions and actions to address this area of unmet need.

\section{Steps to reduce adhesions}

The generally accepted method of reducing adhesions is a meticulous surgical technique [6] and, within that, the rules of microsurgery are fundamental [7]. In particular, they need to be re-emphasised in laparoscopic surgery and in the treatment of endometriosis, where there is heightened inflammatory response and angiogenesis, with a corresponding propensity for adhesion development [7] (Table 1).

Many of the traumas that cause adhesions are a routine part of surgery and, even if adhesion-reduction strategies are adopted, there can be conflicts-meticulous haemostasis is very important but, to achieve this, limiting the use of cautery may be problematic. Therefore, even if meticulous and careful surgical technique is employed, postoperative adhesions are very common [8]. Any type of surgery (however experienced the surgeon) at any site can cause postoperative adhesions and, while surgeons should adopt the adhesion reduction steps as listed in Table 1 during all operations, these steps may not be sufficient to prevent adhesion formation, as evidenced by the SCAR study data $[2,3]$.

Importantly, while surgical adhesiolysis is the current method of managing adhesions, regardless of the method of adhesiolysis or the type of adhesion, it results in further traumatic disruption and a high rate of adhesion reforma-

Table 1 Adhesion-reduction steps

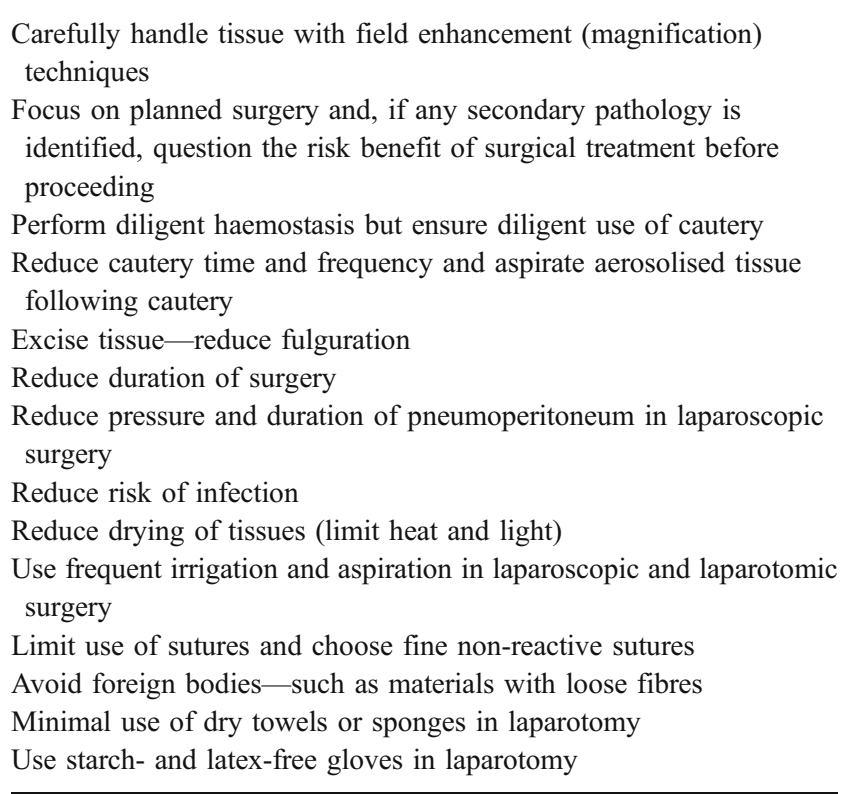

tion (mean $85 \%$ ), as well as the development of de novo adhesions [9]. Studies indicate that, compared with unaffected peritoneal tissue, adhesive tissue contains higher levels of growth factors, suggesting a greater propensity for adhesion reformation. These factors (fibroblast growth factor) depress fibrinolytic activity and induce tissue fibrosis and, thus, reformed adhesions tend to be more dense and severe than de novo adhesions $[10,11]$.

\section{Adhesion-reduction agents}

A number of adjuvants and strategies have been investigated, including both pharmacological agents and physical barriers. Decisions on which agent to use are made by the individual surgeon but there is a clear place for agents that are safe, simple to use, clinically effective and affordable.

The quality of research on the use of adhesion-reduction agents is, unfortunately, variable. Most studies have looked at reduction in adhesions as the endpoint. In the majority of cases, the studies have compared the use of an agent with no treatment, sometimes in the same patient. Few studies have been blinded, with most evaluations of adhesion reduction made by the operating surgeon. The variation in adhesion classifications, mode of application of agents, lack of uniformity in surgical approaches and variations in the interpretation of results all make the assessment of the efficacy of the many agents difficult and almost impossible to compare. There are very few studies that have looked at the impact of an agent on clinical outcomes, such as pregnancy, reduction in SBO or ease of reoperative surgery. This is largely because of the complexity of undertaking clinical outcome studies in surgery [12]. Looking at pregnancy as an outcome in women with infertility, which is multi-factorial, is problematic. Likewise, the number of patients needed to power a study to show a reduction in SBO is considerable [12], requiring many centres or a lengthy time period to undertake such work, which can lead to bias with inter-centre and inter-surgeon variables and changes in surgical practice [13]. To date, studies required for regulatory approvals of adhesion-reduction agents have focussed on adhesion reduction [14].

Pharmacological agents

The processes of adhesion formation present various theoretical opportunities for pharmacological intervention. A number of agents have been investigated, including antibiotics, NSAIDs, corticosteroids and fibrinolytics [15, 16]. To date, no clinical studies have shown adhesionreduction benefits using pharmacological regimens [17] and there are safety concerns with some agents [18, 19]. Theoretically, drugs may be limited by their inability to 
reach the site and to stay there long enough to be effective [19], since surgical sites are often poorly vascularised, as are most injury sites. Rapid resorption through the peritoneal membrane occurs with small molecules, thus, removing many agents delivered intraperitoneally. Moreover, many processes involved in adhesion formation are also part of normal wound healing, so any pharmacological agent needs to reduce fibrin deposition, yet still allow for re-epithelialisation.

Research continues on a range of pharmacological agents but they are still at an experimental stage and the practical use of such agents in routine surgery is some way off.

\section{Physical separators}

Barriers are currently the only available adjuncts to reduce adhesion formation. The key requirement of any barrier is that it should effectively separate traumatised peritoneal surfaces during the critical period of adhesion development in the 3-5 days after surgery, during which, peritoneal healing occurs [20].

This separation can broadly be achieved by use of sitespecific mechanical barriers (films and gels) or by the use of broad-coverage fluid agents to keep tissue surfaces physically separated during the healing process.

The available agents are summarised in Table 2 and outlined in the following sections.

Site-specific mechanical barriers

These have been used for some time, initially in the form of omental or peritoneal grafting. More recently, inert barriers have been introduced to be used at the site of trauma; for example, over a suture line for procedures such as myomectomy.

Table 2 Overview of the available anti-adhesion agents

\begin{tabular}{|c|c|c|c|c|c|c|}
\hline \multirow[t]{2}{*}{ Agent } & \multicolumn{2}{|l|}{ Approval } & \multirow[t]{2}{*}{ Safety } & \multirow[t]{2}{*}{ Limitations } & \multirow[t]{2}{*}{ Clinical studies } & \multirow[t]{2}{*}{ Cost } \\
\hline & Europe* & US FDA & & & & \\
\hline \multicolumn{7}{|l|}{ Site-specific } \\
\hline Preclude & $\checkmark$ & $\begin{array}{l}\checkmark \text { Tissue } \\
\text { separation }\end{array}$ & $\checkmark$ & Suture in place & Limited & $€ €$ \\
\hline Interceed & $\checkmark$ & $\checkmark$ Open & $\checkmark$ & $\begin{array}{l}\text { Incompatible with blood } \\
\text { Remove irrigants before use } \\
\text { Handling }\end{array}$ & $\begin{array}{l}\text { Many studies } \\
\text { - One limited pregnancy } \\
\text { outcomes study }\end{array}$ & $€ €$ \\
\hline Seprafilm & $\checkmark$ & $\checkmark$ Open & $\begin{array}{l}\checkmark \text { But } \\
\text { anastomosis }\end{array}$ & $\begin{array}{l}\text { Remove irrigants before use } \\
\text { Handling } \\
\text { Difficult to apply in } \\
\text { laparoscopy }\end{array}$ & $\begin{array}{l}\text { A number of studies } \\
\text { - Laparotomy only } \\
\text { - SBO study - limited results }\end{array}$ & $€ €(€)$ \\
\hline SprayGel & $\checkmark$ & No & $?$ & $\begin{array}{l}\text { Complex and capital } \\
\text { equipment needed }\end{array}$ & $\begin{array}{l}\text { Very limited } \\
\text { - Pivotal study halted }\end{array}$ & $€ € €$ \\
\hline $\begin{array}{l}\text { Hyalobarrier } \\
\text { gel }\end{array}$ & $\checkmark$ & No & $\checkmark$ & $\begin{array}{l}\text { Handling } \\
\text { No irrigation after application }\end{array}$ & $\begin{array}{l}\text { Limited } \\
\text { - One limited pregnancy } \\
\text { outcomes study }\end{array}$ & $€(€)$ \\
\hline SurgiWrap & $\checkmark$ & No & $?$ & $\begin{array}{l}\text { Peritoneal replacement film } \\
\text { No clinical data on adhesion } \\
\text { reduction } \\
\text { Suture in place }\end{array}$ & None & $€ €(€)$ \\
\hline $\begin{array}{l}\text { Oxiplex AP } \\
\text { gel }\end{array}$ & $\checkmark$ & No & $\checkmark$ & Availability & $\begin{array}{l}\text { Very limited } \\
\text { - Pilot studies only }\end{array}$ & $? ?$ \\
\hline \multicolumn{7}{|l|}{ Broad coverage } \\
\hline Adept & $\checkmark$ & $\checkmark$ Lap & $\checkmark$ & $\begin{array}{l}\text { Clinical studies in laparoscopy } \\
\text { only }\end{array}$ & $\begin{array}{l}\text { Limited } \\
\text { - Double blind study } \\
\text { - Active control }\end{array}$ & $€$ \\
\hline
\end{tabular}

* At least one country 
Preclude ${ }^{\circledR}$ (Gore-tex-expanded polytetrafluoroethylene, PTFE)

One of the first physical membranes used was Preclude ${ }^{\circledR}$. It has to be sutured in place and is not resorbable, so it has to be removed at a second laparoscopy, which substantially limits its applicability in peritoneal surgery. Preclude ${ }^{\circledR}$ is rarely used in Europe and resorbable barriers have subsequently been introduced which have greater clinical utility.

\section{Interceed $\AA$ (oxidised regenerated cellulose)}

The first resorbable membrane was Interceed $^{\circledR}$, first introduced in 1990. It forms a viscous gel when it comes into contact with fluids and is completely resorbed after 4 weeks. It can be used at most intraperitoneal locations and in laparoscopic as well as open surgery-although laparoscopic application is challenging [21]. Meticulous haemostasis is important, as the efficacy of the product is reduced in the presence of blood [22, 23]. There is substantial literature on the use of Interceed ${ }^{\circledR}$ in gynaecological surgery and the product has been shown to reduce adhesion formation without affecting wound healing [24-31]. However, the quality of many of the studies is limited by study design, with surgery only as the control. Although a systematic review of the literature in 1999 concluded that no study reported pregnancy or the reduction of pain as an outcome [25], more recent work with Interceed ${ }^{\circledR}$ indicated that its effect on reducing adhesions results in improved pregnancy outcomes in infertile patients [29]. While the number of patients in this study was limited, the use of Interceed ${ }^{\circledR}$ resulted in a significant increase in the pregnancy rate compared to surgical controls. These results are very important for all anti-adhesion agents, as they show that adhesion reduction using an anti-adhesion agent is a valid endpoint.

\section{Seprafilm ${ }^{\circledR}$ (hyaluronic acid/carboxymethylcellulose)}

Seprafilm ${ }^{\circledR}$ is another barrier film [32, 33], which is usually placed over a suture line. It persists during the period of reepithelialisation and is absorbed spontaneously. Seprafilm ${ }^{\circledR}$ does not conform to the shape of the pelvic organs as well as Interceed ${ }^{\circledR}$ and is usually used as a barrier placed between the bowel or omentum and the anterior abdominal wall at the time of wound closure, where it can prevent adherence and, potentially, reduce the risk of enterotomy at subsequent surgery. It is generally difficult to handle and its use in laparoscopic surgery is not realistic. Alongside the main pivotal studies $[32,33]$, there is mounting literature on its use and it is the only agent to have been investigated for the reduction of SBO [34, 35]. This study reported a significant reduction in adhesive small bowel obstruction requiring reoperation by the use of Seprafilm ${ }^{\circledR}(1.6 \%$ absolute reduction) [35]. A mean of 4.5 sheets per patient was used to effect adequate coverage, which is costly [34, 35]. While the study also provided confirmation of general safety in colorectal surgery, it highlighted that the use of Seprafilm ${ }^{\circledR}$ at the site of an anastomosis is to be avoided, due to increased anastomotic leaks [34]. SurgiWrap ${ }^{\circledR}$ (polylactide: copolymer of 70:30 Poly
[L-lactide-co-D,L lactide])

SurgiWrap ${ }^{\circledR}$ is a biodegradable polymer film which has a European device licence for the reduction of postoperative adhesions following abdominal, pelvic, gynaecological or cardiac surgery. The supplying company claims that the product has improved handling over alternative film products and a long resorption period of up to 6 months, after which, it is subsequently metabolised to lactic acid, $\mathrm{CO}_{2}$ and water. The polymer film needs to be sutured in place to prevent it from moving during this period. With the exception of one preclinical study in 44 rats [36], published data are lacking on which to assess the product's safety or its efficacy in reducing peritoneal adhesions. In light of failures of other agents due to long-term safety concerns and in the absence of evidence of clinical efficacy, the use of SurgiWrap ${ }^{\circledR}$ as an adhesion-reduction agent is not to be encouraged at this time.

\section{Gel barriers}

A fundamental limitation of site-specific mechanical barriers is the requirement of the surgeon to predict where clinically significant adhesions are likely to form in order to decide where to place the product. In addition, site-specific barriers are difficult to use in laparoscopic surgery. As a result of these limitations, gel barriers have also been developed.

\section{Hyalobarrier ${ }^{\circledR}$ (hyaluronic acid cross-linked to hyaluronic acid)}

Hyalobarrier ${ }^{\circledR}$ is a viscous gel, available in Europe as an adhesion-reduction barrier for use after abdominopelvic surgery. It is similar in mode of action to local site-specific film barriers, as it stays at the site to which it is applied, dissolving some days later. There are few published clinical data: there is a small uncontrolled study in myomectomy by laparotomy [37] and two randomised, controlled studies in patients undergoing laparoscopic myomectomy [38, 39]. Although the studies only used limited numbers of patients, they showed a reduction in adhesions and, in the smaller study [38], the pregnancy rate in patients treated with 
Hyalobarrier ${ }^{\circledR}$ was significantly greater than in the control group (surgical treatment only) [40] and similar to that seen with Interceed ${ }^{\circledR}[29]$. Hyalobarrier ${ }^{\circledR}$ is not widely available nor has it been adopted for clinical use in surgery, mainly because it is very sticky and has a tendency to float away from sites when irrigated. These mucoadhesive properties are essential for its efficacy and irrigation is not recommended. However, it has been researched for use in reducing intrauterine adhesions following hysteroscopic surgery with success [41-43] and may be useful in this situation.

\section{SprayGel® (synthetic polyethylene glycol (PEG) solutions)}

SprayGel ${ }^{\circledR}$ is a gel barrier coating system which was approved for use in laparoscopic and open surgery in Europe at the end of 2001. It consists of two water-based PEG solutions, one clear and one coloured with methylene blue, to make it easy to see where it has been used. When sprayed together, these two solutions react with each other at the target tissue, where they mix to form a hydrogel film that provides a physical barrier. This barrier remains in place for up to 7 days and is then absorbed and excreted through the kidneys.

In preliminary clinical trials, the use of SprayGel ${ }^{\circledR}$ resulted in a decrease in the incidence, severity and extent of post-surgical adhesion formation [44, 45]. A larger scale pivotal study had commenced in the USA but was then stopped due to lack of efficacy in the treatment compared to the control arm and has not, to date, been resumed.

The use of SprayGel ${ }^{\circledR}$ is limited by the complex setting up of the equipment and the skill and time required to spray and coat tissues evenly. It is also expensive. If there is extensive operative surgery in the pelvis as well as abdominal adhesiolysis, it may be necessary to use two kits and as many as five kits to effect adequate coverage of the complete peritoneal wound area [46].

\section{Oxiplex $\mathbb{\circledR} / A P$ (carboxymethylcellulose (CMC) \\ and polyethylene oxide (PEO) composite gel)}

Most recently, Oxiplex ${ }^{\circledR} / \mathrm{AP}$, a viscoelastic gel, has been approved for use in Europe as an adhesion-reduction barrier for abdominal/pelvic surgery. It has been used in another formulation for a number of years for the reduction of adhesions in spinal surgery [47]. Two clinical pilot studies in laparoscopic gynaecological surgery comparing use of this gel with no treatment have recently been published $[48,49]$. They are primarily safety studies and are, thus, empowered to assess the safety and not the efficacy of the agent. However, in both studies, there was an improvement in the American Fertility Society (AFS) scores compared to the no-treatment controls and the
European pilot study demonstrated a significant reduction in adnexal adhesions [48].

These gel agents, like the film barriers, are site-specific, requiring surgeons to predict sites at which adhesions may form and, thus, where the film barrier needs to be applied. However, the pathogenesis of adhesion formation reaches beyond the operative site of actual surgical trauma. The effects of ischaemia, heat, drying, handling and contamination mean that agents providing protection throughout the peritoneal cavity could be advantageous.

\section{Broad-coverage fluid agents}

Various broad-coverage agents have been developed but most have been abandoned (Hyskon ${ }^{\circledR}[50]$ ) or withdrawn due to safety issues (Intergel ${ }^{\circledR}$ [51]) or the lack of efficacy (Hyskon ${ }^{\circledR}$ [52], Sepracoat ${ }^{\circledR}$ ).

Hydroflotation has long been suggested as a technique that may be efficacious, both at the site of application and elsewhere in the pelvis. It involves the instillation of a fluid into the peritoneal cavity at the end of the procedure to provide a physical fluid barrier, preventing the apposition of damaged peritoneal surfaces. Saline, lactated Ringer's solution or Hartmann's solution have all been used widely. However, these crystalloid solutions are absorbed rapidly and do not reduce adhesions [53]. They are absorbed from the peritoneal cavity at the rate of $30-50 \mathrm{ml}$ per hour, so that, by 24 hours after surgery, little, if any, solution is left in the pelvis [54-56]. Studies have also shown that some irrigants, including lactated Ringer's solution, can have deleterious effects on the delicate mesothelial lining of the peritoneum $[57,58]$.

\section{Adept ${ }^{\circledR}$ (4\% icodextrin solution)}

Adept $^{\circledR}$ is the single approved and available adhesionreduction solution that has a sufficiently long intraperitoneal residence [59] to provide coverage throughout the peritoneal cavity and persist through the critical period of adhesion formation [20]. Adept ${ }^{\circledR}$ has been approved in Europe since 2000 as an adhesion-reduction agent in open and laparoscopic gynaecological and general surgery. In the USA, it was recently approved by the FDA for use as an irrigant and post-operative instillate in gynaecological laparoscopy with adhesiolysis. It is the first anti-adhesion agent to be granted such approval. Adept $^{\circledR}$ is a non-viscous, iso-osmotic, clear solution which handles like normal saline, requires no change to surgical practice or any special training. It does not potentiate infection [60] and no differences have been demonstrated between Adept ${ }^{\circledR}$ and lactated Ringer's solution (LRS) in the healing and strength of midline incisions and bowel anastomoses [61]. 
Early work with Adept $^{\circledR}$ as an anti-adhesion agent showed that it is best used throughout surgery as an irrigant fluid to reduce dessication and following surgery as an instillate $(1000 \mathrm{~mL})[60,62]$; all work with Adept $^{\circledR}$ has used this combined approach.

Initial clinical studies were encouraging [62] and, recently, efficacy has been further established in a pivotal randomised USA multi-centre study in gynaecological laparoscopy [63]. This study is the largest and the first double-blind study of an anti-adhesion agent. As well as confirming the safety of Adept ${ }^{\mathbb{R}}$, the data demonstrate a significant reduction in adhesions throughout the peritoneal cavity when $\operatorname{Adept}^{\circledR}$ is used as an irrigant and postoperative instillate.

A European patient registry (ARIEL) for Adept ${ }^{\circledR}$ use was established alongside the formal clinical trial programme, providing surgeons' feedback on the use and safety of $\operatorname{Adept}^{\circledR}$ in routine open and laparoscopic gynaecological [64] and general surgery [65] in 4,620 patients - 2,882 of whom underwent gynaecological surgery (2,069 laparoscopy, 813 laparotomy). The study showed that, in routine use, Adept ${ }^{\circledR}$ is well tolerated by patients, is easy to use and has a good safety profile.

\section{Areas of future research}

\section{Laparoscopic pneumoperitoneum}

While it is widely considered that laparoscopy may be less adhesiogenic than laparotomy, there are some inconsistencies when epidemiological data on adhesion-related outcomes are considered [3]. Since laparoscopy is minimally invasive and, thus, associated with less surgical trauma than laparotomy, there is rising concern that the $\mathrm{CO}_{2}$ pneumoperitoneum may be an important adhesiogenic factor. This may be due to the $\mathrm{CO}_{2}$ inducing local changes such as intraperitoneal acidosis [66-68] or, in the absence of moistening, dessication of the mesothelium [69]. The intraperitoneal pressure associated with prolonged pneumoperitoneum may also induce adverse effects on the microcirculation [70,71], possibly inducing hypoxaemia [72]. This hypoxia, together with other mesothelial insult, may stimulate the expression of factors such as vascular endothelial growth factor (VEGF), resulting in an increase in adhesion formation [72]. As a result of this animal work, active research for other potential adhesion-reduction strategies involving insufflators has begun [73, 74].

\section{Cost-effectiveness of anti-adhesion agents}

Post-operative adhesions clearly have an important impact on the successful clinical outcome of surgery and pose an important cost burden. In considering the use of an adhesion-reduction agent, factors to be taken into consideration include not only its safety, ease of use and clinical efficacy, but also whether it is cost-effective. While it is difficult to evaluate the impact that an anti-adhesion agent will have on subsequent clinical outcomes and, thus, whether it will be cost-effective [12], it is possible to model this.

Epidemiological data from the SCAR study [75] have been used to model the cumulative costs over time of adhesion-related hospital readmissions following surgery with or without the use of an adhesion-reduction agent [12] and have recently been updated with the costs of inflation. This model is helpful in understanding the value of different adhesion-reduction agents and suggests that a suitably priced and effective agent can result in overall cost savings to a healthcare system. For example, agents costing around $€ 130$ only need to demonstrate a $26 \%$ reduction in adhesion-related readmissions 3 years after surgery to return their costs, whereas agents costing around $€ 300$ per operation would need to demonstrate at least a $60 \%$ reduction in adhesion-related readmissions 3 years after surgery to return the costs of their investment (Fig. 1) [12].
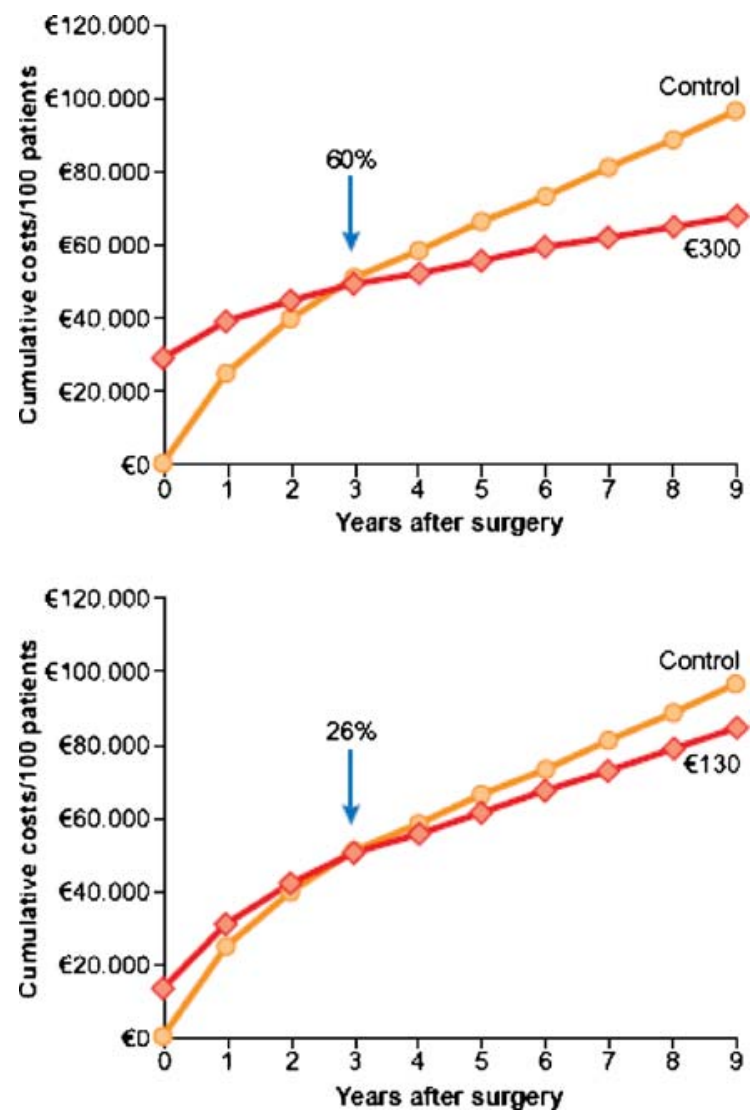

Fig. 1 Cumulative costs of adhesion-related readmissions for 100 patients, following surgery with or without an adhesion-reduction agent. Modelled on the efficacy required to pay back the cost of treatment after 3 years [12] for $€ 130$ and $€ 300$ agent costs 
In either scenario, extension of the model assessment period beyond 3 years after surgery results in cost savings.

It is clear from this that, in considering the choice of an adhesion-reduction agent, the cost as well as the clinical impact of the agent needs to be considered carefully. This is particularly the case if the prophylactic use of adhesionreduction agents is to be adopted widely in routine surgery.

\section{Advising patients and medicolegal considerations}

Even with advances in surgical techniques, it is clear that adhesions remain a common consequence of surgery, with serious health implications for patients, including SBO, infertility and chronic pelvic pain. Even if adhesions are "silent," posing no apparent issues for the patient, the risks of complications at reoperative surgery and late SBO onset are considerable.

Adhesion-related complications are increasingly becoming the subject of forensic and medicolegal debate and there is evidence that medicolegal litigation resulting from complications secondary to postoperative adhesion formation are adding to the healthcare costs and the clinician's burden [76, 77].

In the consent process, it is recommended that patients should be advised of the reasons for and nature of the procedure, the benefits, risks, discomforts and alternatives and the consequences of not undergoing the procedure.

It is common practice in the consent process to advise patients of risks of complications, such as general anaesthesia $(<1: 100)$, and general complications after laparoscopic surgery, e.g. pain, bleeding, infection, damage to the bowel/bladder/urethra (1:1000 in sterilisations and 1:500 for other procedures) [78]. These risk ratios are less than the risk of a directly adhesion-related readmission (adhesiolysis) in the first year after surgery following a known high-risk laparoscopic procedure, such as an ovarian or tubal procedure, or open ovarian surgery (1:80 following laparoscopic surgery and 1:50 following open surgery). Even in patients undergoing other therapeutic laparoscopic surgery (excepting tubal sterilisations), the risk of a directly adhesion-related readmission is 1:70 and, for open surgery on the Fallopian tubes or uterus, it is $1: 120$ and 1:170, respectively, i.e. comparatively high [3].

The International Adhesions Society undertook a survey to review the information on adhesions that patients received $[79,80]$. In only $10.4 \%$ of cases were adhesions mentioned as part of the informed consent process and in $14.4 \%$ adhesions were discussed but were not part of the consent process. In patients undergoing specific adhesiolysis surgery, 54\% reported being given some kind of information about adhesions but only $46 \%$ were given information on adhesion-reduction agents. In procedures not involving adhesiolysis, only $10 \%$ of patients reported receiving any adhesion information and only $6 \%$ were given information on adhesion-reduction agents.

Tissue damage to underlying structures during laparoscopic surgery has been shown to be the most common cause of successful surgical negligence suits [81] and it is estimated that the risk of bowel injury is between $10 \%$ and $25 \%$ of laparoscopic adhesiolysis cases [82] and there is a $19 \%$ risk of inadvertent enterotomy during reoperative laparotomy [83]. Furthermore, in a study of misadventure data following laparoscopic surgery, while injury to the common bile duct was the most frequent problem, perforation of the small bowel or colon was the second most common injury and two-thirds of injuries were not noted until after the end of the surgical procedure [84]. Risk of damage was greater when there were difficulties visualising structures-which can be a common issue when operating on a patient with pre-existing adhesions.

With published evidence suggesting that the long-term risk of adhesion-related complications is high in the majority of gynaecological procedures, there is an urgent need for gynaecologists to be cognisant of the potential for medicolegal action $[76,77,85]$ if patients are not informed routinely of the risk of adhesions.

\section{Consensus on how to avoid adhesions}

To reduce the risk of adhesions, surgeons should actively consider adopting anti-adhesion strategies as described in Table 1, particularly in "high-risk" gynaecological procedures (whether open or laparoscopic), such as ovarian, endometriosis or tubal surgery, myomectomy and adhesiolysis.

New developments in anti-adhesion products and our practical knowledge of using such agents has increased in recent years. Not all agents are difficult or costly to use and there is now promising evidence of efficacy, not only in the reduction of adhesions, but also in subsequent outcomes, such as reduction in SBO or improvement in pregnancy rates in infertile women.

At present, surgeons largely employ good surgical practice to prevent adhesion formation and adhesiolysis to treat adhesions-despite the high reformation rate [9]. Sound epidemiological studies have shown that, even with advances in surgical practice, adhesions continue to represent a significant burden for patients, surgeons and healthcare systems. Evidence is increasing to support the efficacy of adhesion-reduction agents to complement good surgical practice, including agents that are relatively inexpensive and simple to use (Table 2).

It is also time to advise our patients of the risks associated with adhesion-related complications during the 
consent process. Failure to inform patients adequately of the risks could, indeed, result in claims of medical negligence.

Further research on the use of adhesion-reduction agents is essential to better understand their impact on clinical outcomes, recognising that such studies are difficult to undertake [12]. Research also needs to continue into the use of more effective adhesion-preventative agents and combinations of strategies and agents. All surgeons should act now to reduce adhesions, thereby, fulfilling their duty of care to patients.

As the results of further studies on adhesions and adhesion-reduction agents become available, the consensus proposals below should be reviewed.

Consensus proposals: actions to reduce adhesions

1. Adhesions need to be recognised as the most frequent complication of abdominal surgery.

2. Surgeons, other healthcare workers, budget holders and policy makers need to increase their awareness and understanding of adhesions and the associated healthcare burden and costs and take active steps to reduce this.

3. Patients need to be informed of the risk of adhesions, given that adhesions are now the most frequent complication of abdominal surgery.

4. Surgeons who do not advise of the risk of adhesions may put themselves at risk of claims for medical negligence.

5. Surgeons have a duty of care to protect patients by providing the best possible standards of care-which should include taking steps to reduce adhesion formation.

6. Surgeons should adopt a routine adhesion-reduction strategy, at least in surgery at high risk for adhesions, such as:

- Ovarian surgery

- Endometriosis surgery

- Tubal surgery

- Myomectomy

- Adhesiolysis

7. Good surgical technique is fundamental to any adhesionreduction strategy—see Table 1

8. Surgeons should consider the use of adhesion-reduction agents as part of their adhesion-reduction strategy, giving special consideration to agents with data to support safety in routine abdominopelvic surgery and efficacy in reducing adhesions. The practicality and ease of use of agents, as well as the cost of any agent, will influence their acceptability in routine practice.

9. Further research to understand the impact that adhesionreduction agents have on clinical outcomes will be important.

10. Research towards more effective preventative agents should be encouraged-including the use of combinations of agents to prevent the formation of de novo adhesions, as well as adhesion reformation.

11. Surgeons need to act now to reduce adhesions and fulfil their duty of care to patients.
Acknowledgements The consensus project and manuscript development was facilitated by Corvus Communications Limited under the direction of Rudy DeWilde and Geoffrey Trew. Special thanks go to the work of Alison Crowe, Alastair Knight and Jill Kirkdale in patiently supporting and encouraging all Adhesions Working Party members to actively contribute and feed back on all stages of the project development.

\section{Appendix}

Expert Adhesions Working Party of the ESGE

Members of the Expert Adhesions Working Party of the European Society of Gynaecological Endoscopy (ESGE) are listed below alphabetically. All members actively contributed to the development and review of the consensus paper, recognising the importance of publishing on a matter of such importance. The majority participated at the Adhesions Consensus Expert Workshop convened during the 15th Annual Congress of the ESGE and the project was progressed in accordance with accepted processes for the development of consensus statements (see Consensus Process including Conflict of Interest in part 1 published in the previous issue of Gynecological Surgery [86])

Prof. Rudy Leon DeWilde, Pius Hospital, Oldenburg, Germany

Mr. Geoffrey Trew, Hammersmith Hospital, London, UK

Dr. Stefano Angioni, H San Giovanni di Dio, Cagliari, Italy

Prof. Alain Audebert, Rue de Turenne, Bordeaux, France

Prof. Pedro Barri, Institut Universitari Dexeus, Barcelona, Spain

Prof. Charles Chapron, Clinique Universitaire Baudeloque, Paris, France

Prof. Maria Elisabetta Coccia, Ospedale di Careggi, Florence, Italy

Prof. Michel Degueldre, Centre Hospitalier Universitaire St-Pierre, Brussels, Belgium

Prof. Gere diZerega, Keck School of Medicine, University of Southern California, Los Angeles, USA

Prof. Enrique Garcia, Instituto Valenciano de Oncologia, Valencia, Spain

Dr. Robert J S Hawthorn, Southern General Hospital, Glasgow, Scotland

Dr. Petra Janssen, Klinikum Konstanz, Konstanz, Germany

Prof. Philippe R Koninckx, University Hospital Gasthuisberg, Leuven, Belgium

Prof. Matthias Korell, Klinikum Duisburg, Wedau Kliniken, Duisburg, Germany

Dr. Stefano Landi, Ospedale Sacro Cuore, Verona, Italy Mr. Adrian M Lower, The London Clinic, London, UK 
Prof. Per Lundorff, Kvindeafdelingen, Viborg Sygehus, Denmark

Dr. Enda McVeigh, John Radcliffe Hospital, Oxford, UK Prof. Patrick Madelenat, Hôpital Bichat, Paris, France

Prof. Valerio Mais, H San Giovanni di Dio, Cagliari, Italy

Prof. Gian Benedetto Melis, H San Giovanni di Dio, Cagliari, Italy

Prof. Luca Minelli, Ospedale Sacro Cuore, Verona, Italy

Prof. Carmine Nappi, Università degli studi di Napoli

Federico II, Naples, Italy

Prof. Michelle Nisolle, University of Liege, Liege, Belgium

Prof. George Pados, Interbalkan European Medical Center (Diavalkanino), Thessaloniki, Greece

Prof. George Pistofidis, AKESO, Gynaecology \& Reproductive Centre, Athens, Greece

Dr. Massimillano Pellicano, Università degli studi di Napoli Federico II, Naples, Italy

Prof. Jean Luc Pouly, Polyclinique de l'Hôtel-Dieu, Clermont-Ferrand, France

Prof. Stefan Rimbach, Klinikum Konstanz, Konstanz, Germany

Prof. Ernst Schmidt, Diakonie-Krankenhaus GmbH (Frauenklinik), Bremen, Germany

Prof. Christopher Sutton, The Guildford Nuffield Hospital, Guildford, UK

Dr. Alicia Ubeda, Institut Universitari Dexeus, Barcelona, Spain

Prof. Diethelm Wallwiener, Universitäts-Frauenklinik Tübingen, Tübingen, Germany

Prof. Arnaud Wattiez, IRCAD (Institut de Recherche contre les Cancers de l'Appareil Digestif), Hôpitaux Universitaires, Strasbourg, France

Prof. Errico Zupi, S. Giovanni calibita Fatebenefratelli Isola Tiberina, Rome, Italy

\section{References}

1. Diamond MP, El-Hammady E, Wang R, Kruger M, Saed G (2004) Regulation of expression of tissue plasminogen activator and plasminogen activator inhibitor-1 by dichloroacetic acid in human fibroblasts from normal peritoneum and adhesions. Am J Obstet Gynecol 190:926-934

2. Lower AM, Hawthorn RJS, Ellis H, O'Brien F, Buchan S, Crowe AM (2000) The impact of adhesions on hospital readmissions over ten years after 8849 open gynaecological operations: an assessment from the Surgical and Clinical Adhesions Research Study. Br J Obstet Gynaecol 107:855-862

3. Lower AM, Hawthorn RJS, Clark D, Boyd JH, Finlayson AR, Knight AD et al (2004) Adhesion-related readmissions following gynaecological laparoscopy or laparotomy in Scotland: an epidemiological study of 24,046 patients. Hum Reprod 19:1877-1885

4. Diamond MP, Daniell JF, Feste J, Surrey MW, McLaughlin DS, Friedman $S$ et al (1987) Adhesion reformation and de novo adhesion formation after reproductive pelvic surgery. Fertil Steril 47:864-866

5. Pados GA, Devroey P (1992) Adhesions. Curr Opin Obstet Gynecol 4:412-418

6. Monk BJ, Berman ML, Monitz FJ (1994) Adhesions after extensive gynecologic surgery: clinical significance, etiology, and prevention. Am J Obstet Gynecol 170:1396-1403

7. Canis M, Botchorishvili R, Tamburro S, Safi A, Wattiez A, Mage $G$ et al (2001) Adhesion prevention in the surgical treatment of pelvic endometriosis. Gynaecol Endosc 10:99-106

8. Menzies D, Ellis H (1990) Intestinal obstruction from adhesionshow big is the problem? Ann R Coll Surg Engl 72:60-63

9. Diamond MP, Freeman ML (2001) Clinical implications of postsurgical adhesions. Hum Reprod Update 7:567-576

10. Holmdahl L, Eriksson E, Eriksson BI, Risberg B (1998) Depression of peritoneal fibrinolysis during operation is a local response to trauma. Surgery 123:539-544

11. Ivarsson ML, Bergström M, Eriksson E, Risberg B, Holmdahl L (1998) Tissue markers as predictors of postoperative adhesions. Brit J Surg 85:1549-1554

12. Wilson MS, Menzies D, Knight AD, Crowe AM (2002) Demonstrating the clinical and cost effectiveness of adhesion reduction strategies. Colorectal Dis 4:355-360

13. Salum M, Wexner SD, Nogueras JJ, Weiss E, Kouda M, Behrens K et al (2006) Does sodium hyaluronate- and carboxymethylcellulosebased bioresorbable membrane (Seprafilm) decrease operative time for loop ileostomy closure? Tech Coloproctol 10:187-191

14. U.S. Department of Health and Human Services/U.S. Food and Drug Administration (2002) Guidance for resorbable adhesion barrier devices for use in abdominal and/or pelvic surgery. Available online at http://www.fda.gov/cdrh/ode/guidance/1356. pdf

15. diZerega GS (1994) Contemporary adhesion prevention. Fertil Steril 61:219-235

16. Rodgers KE, diZerega GS (2000) Developing pharmacologic agents for adhesion prevention. In: diZerega GS (ed) Peritoneal surgery. Springer-Verlag, New York, pp 441-457

17. Metwally M, Watson A, Lilford R, Vandekerckhove P (2006) Fluid and pharmacological agents for adhesion prevention after gynaecological surgery. Cochrane Database of Systematic Reviews, Issue 2. Art. No.:CD001298. DOI 10.1002/14651858. CD001298.pub3

18. El-Morafi DM, Diamond MP (2003) Are pelvic adhesions preventable? Surg Technol Int 11:222-235

19. Risberg B (1997) Adhesions: preventive strategies. Eur J Surg (Suppl 577):32-39

20. Harris ES, Morgan, RF, Rodeheaver GT (1995) Analysis of the kinetics of peritoneal adhesion formation in the rat and evaluation of potential antiadhesive agents. Surgery 117:663-669

21. Pados G, Camus M, De Munck L, Devroey P (1992) Laparoscopic application of Interceed (TC7). Hum Reprod 7:1141-1143

22. Wallwiener D, Meyer A, Bastert G (1998) Adhesion formation of the parietal and visceral peritoneum: an explanation for the controversy on the use of autologous and alloplastic barriers? Fertil Steril 69:132-137

23. Azziz R, Murphy AA, Rosenberg SM, Patton GW Jr (1991) Use of an oxidized, regenerated cellulose absorbable adhesion barrier at laparoscopy. J Reprod Med 36:479-482

24. Interceed (TC7) Adhesion Barrier Study Group (1989) Prevention of postsurgical adhesions by INTERCEED (TC7), an absorbable adhesion barrier: a prospective randomized multicenter clinical study. Fertil Steril 51:933-938

25. Farquhar C, Vandekerckhove P, Watson A, Vail A, Wiseman D (1999) Barrier agents for preventing adhesions after surgery for subfertility. Cochrane Database of Systematic Reviews, Issue 2. Art No.:CD000475. DOI 10.1002/14651858.CD000475 
26. Larsson B (1996) Efficacy of Interceed in adhesion prevention in gynecologic surgery: a review of 13 clinical studies. J Reprod Med 41:27-34

27. Wiseman DM, Trout JR, Franklin RR, Diamond MP (1999) Metaanalysis of the safety and efficacy of an adhesion barrier (Interceed TC7) in laparotomy. J Reprod Med 44:325-331

28. Nordic Adhesion Prevention Study Group (1995) The efficacy of Interceed(TC7)* for prevention of reformation of postoperative adhesions on ovaries, fallopian tubes, and fimbriae in microsurgical operations for fertility: a multicenter study. Fertil Steril 63:709-714

29. Sawada T, Nishizawa H, Nishio E, Kadowaki M (2000) Postoperative adhesion prevention with an oxidized regenerated cellulose adhesion barrier in infertile women. J Reprod Med 45:387-389

30. Mais V, Ajossa S, Piras B, Guerriero S, Marongiu D, Melis GB (1995) Prevention of de-novo adhesion formation after laparoscopic myomectomy: a randomized trial to evaluate the effectiveness of an oxidized regenerated cellulose absorbable barrier. Hum Reprod 10:3133-3135

31. Keckstein J, Ulrich U, Sasse V, Roth A, Tuttlies F, Karageorgieva E (1996) Reduction of postoperative adhesion formation after laparoscopic ovarian cystectomy. Hum Reprod 11:579-582

32. Diamond MP; The Seprafilm Adhesion Study Group (1996) Reduction of adhesions after uterine myomectomy by Seprafilm membrane (HAL-F): a blinded, prospective, randomized, multicenter clinical study. Fertil Steril 66:904-910

33. Becker JM, Dayton MT, Fazio VW, Beck DE, Stryker SJ Wexner SD et al (1996) Prevention of postoperative abdominal adhesions by a sodium hyaluronate-based bioresorbable membrane: a prospective, randomized, double-blind multicenter study. J Am Coll Surg 183:297-306

34. Beck DE, Cohen Z, Fleshman JW, Kaufman HS, van Goor H, Wolff BG et al (2003) A prospective, randomized, multicenter, controlled study of the safety of Seprafilm adhesion barrier in abdominopelvic surgery of the intestine. Dis Colon Rectum 46:1310-1319

35. Fazio VW, Cohen Z, Fleshman JW, van Goor H, Bauer JJ, Wolff BG et al (2006) Reduction in adhesive small-bowel obstruction by Seprafilm ${ }^{\circledR}$ adhesion barrier after intestinal resection. Dis Colon Rectum 49:1-11

36. Avital S, Bollinger TJ, Wilkinson JD, Marchetti F, Hellinger MD, Sands LR (2005) Preventing intra-abdominal adhesions with polylactic acid film: an animal study. Dis Colon Rectum 48:153-157

37. Carta G, Cerrone L, Iovenitti P (2004) Postoperative adhesion prevention in gynecologic surgery with hyaluronic acid. Clin Exp Obstet Gynecol 31:39-41

38. Pellicano M, Bramante S, Cirillo D, Palomba S, Bifulco G, Bellato P et al (2003) Effectiveness of autocrosslinked hyaluronic acid gel after laparoscopic myomectomy in infertile patients: a prospective, randomized, controlled study. Fertil Steril 80:441444

39. Mais V, Bracco GL, Litta P, Gargiulo T, Melis GB (2006) Reduction of postoperative adhesions with an auto-crosslinked hyaluronan gel in gynaecological laparoscopic surgery: a blinded, controlled, randomized, multicentre study. Hum Reprod 21:12481254

40. Pellicano M, Guida M, Bramante S, Acunzo G, Di Spiezio Sardo AG, Tommaselli $G$ et al (2005) Reproductive outcome after autocrosslinked hyaluronic acid gel application in infertile patients who underwent laparoscopic myomectomy. Fertil Steril 83:498500

41. Acunzo G, Guida M, Pellicano M, Tommaselli GA, Di Spiezio Sardo A, Bifulco G et al (2003) Effectiveness of auto-cross-linked hyaluronic acid gel in the prevention of intrauterine adhesions after hysteroscopic adhesiolysis: a prospective, randomized, controlled study. Hum Reprod 18:1918-1921

42. De Iaco PA, Muzzupapa G, Bovicelli A, Marconi S, Bitti SR, M Sansovini et al (2003) Hyaluronan derivative gel (Hyalobarrier ${ }^{\circledR}$ gel) in intrauterine adhesion (IUA) prevention after operative hysteroscopy. Ellipse 19:3-6

43. Guida M, Acunzo G, Di Spiezio Sardo A, Bifulco G, Piccoli R, Pellicano $M$ et al (2004) Effectiveness of auto-cross-linked hyaluronic acid gel in the prevention of intrauterine adhesions after hysterosocopic surgery: a prospective, randomized, controlled study. Hum Reprod 19:1461-1464

44. Mettler L, Audebert A, Lehmann-Willenbrock E, Schieve K, Jacobs VR (2003) Prospective clinical trial of SprayGel as a barrier to adhesion formation: an interim analysis. J Am Assoc Gynecol Laparosc 10:339-344

45. Johns DA, Ferland R, Dunn R (2003) Initial feasibility study of a sprayable hydrogel adhesion barrier system in patients undergoing laparoscopic ovarian surgery. J Am Assoc Gynecol Laparosc $10: 334-338$

46. Korrell M (2004) Endometriosis: a common cause of pelvic pain. Adhes News Views 5:18-19

47. Kim KD, Wang JC, Robertson DP, Brodke DS, BenDebba M, Block KM et al (2004) Reduction of leg pain and lower-extremity weakness for 1 year with Oxiplex/SP gel following laminectomy, laminotomy, and discectomy. Neurosurg Focus 17:1-6

48. Lundorff P, Donnez J, Korell M, Audebert AJM, Block K, diZerega GS (2005) Clinical evaluation of a viscoelastic gel for reduction of adhesions following gynaecological surgery by laparoscopy in Europe. Hum Reprod 20:514-520

49. Young P, Johns A, Templeman C, Witz C, Webster B, Ferland R et al (2005) Reduction of postoperative adhesions after laparoscopic gynecological surgery with Oxiplex/AP Gel: a pilot study. Fertil Steril 84:1450-1456

50. Gauwerky JF, Heinrich D, Kubli F (1986) Complications of intraperitoneal dextran application for prevention of adhesions. Biol Res Pregnancy Perinatol 7:93-97

51. Food and Drug Administration MedWatch (2003) Safety AlertINTERGEL Adhesions Prevention Solution. The FDA Safety Information and Adverse Event Reporting Program. Available online at http://www.fda.gov/medwatch/SAFETY/2003/intergel.htm

52. Rosenberg SM, Board JA (1984) High-molecular weight dextran in human infertility surgery. Am J Obstet Gynecol 148:380-385

53. Wiseman DM, Trout JR, Diamond MP (1998) The rates of adhesion development and the effects of crystalloid solutions on adhesion development in pelvic surgery. Fertil Steril 70:702-711

54. Shear L, Swartz C, Shinaberger JA, Barry KG (1965) Kinetics of peritoneal fluid absorption in adult man. N Engl J Med 272:123-127

55. Duffy DM, diZerega GS (1996) Adhesion controversies: pelvic pain as a cause of adhesions, crystalloids in preventing them. $\mathrm{J}$ Reprod Med 41:19-26

56. Hart R, Magos A (1996) Laparoscopically instilled fluid: the rate of absorption and the effects on patient discomfort and fluid balance. Gynaecol Endosc 5:287-291

57. Yaacobi Y, Goldberg EP, Habal MB (1991) Effect of Ringer's lactate irrigation on the formation of postoperative abdominal adhesions. J Invest Surg 4:31-36

58. van Westreenen M, van den Tol PM, Pronk A, Marquet RL, Jeekel J, Lequit P (1999) Perioperative lavage promotes intraperitoneal adhesion in the rat. Eur Surg Res 31:196-201

59. Hosie K, Gilbert JA, Kerr D, Brown CB, Peers EM (2001) Fluid dynamics in man of an intraperitoneal drug delivery solution: $4 \%$ icodextrin. Drug Delivery 8:9-12

60. Verco SJS, Peers EM, Brown CB, Rodgers KE, Roda N, diZerega G (2000) Development of a novel glucose polymer solution (icodextrin) for adhesion prevention: pre-clinical studies. Hum Reprod 15:1764-1772 
61. Rodgers KE, Verco SJS, diZerega GS (2003) Effects of intraperitoneal $4 \%$ icodextrin solution on the healing of bowel anastomoses and laparotomy incisions in rabbits. Colorectal Dis 5:324-330

62. diZerega GS, Verco SJS, Young P, Kettel M, Kobak W, Martin D et al (2002) A randomized, controlled pilot study of the safety and efficacy of $4 \%$ icodextrin solution in the reduction of adhesions following laparoscopic gynaecological surgery. Hum Reprod 17:1031-1038

63. Brown CB, Luciano AA, Martin D, Peers E, Scrimgeour A, diZerega GS, on behalf of the Adept Adhesion Reduction Study Group (2007) Adept (icodextrin 4\% solution) reduces adhesions after laparoscopic surgery for adhesiolysis: a doubleblind, randomized, controlled study. Fertil Steril. DOI 10.1016/j. fertnstert.2006.12.084

64. Menzies D, Pascual MH, Walz MK, Duron JJ, Tonelli F, Crowe A et al (2006) Use of icodextrin 4\% solution in the prevention of adhesion formation following general surgery: from the multicentre ARIEL Registry. Ann R Coll Surg Engl 88:375-382

65. Sutton C, Minelli L, Garcia E, Korell M, Pouly JL, Pados G et al (2005) Use of icodextrin 4\% solution in the reduction of adhesion formation after gynaecological surgery. Gynecol Surg 2:287-296

66. Volz J, Köster S, Weiss M, Schmidt R, Urbaschek R, Melchert F et al (1996) Pathophysiologic features of a pneumoperitoneum at laparoscopy: a swine model. Am J Obstet Gynecol 174:132-140

67. Volz J, Köster S, Leweling H (1997) Surgical trauma and metabolic changes induced by surgical laparoscopy versus laparotomy. Gynecol Endosc 6:1-6

68. West MA, Hackam DJ, Baker J, Rodriguez JL, Bellingham J, Rotstein OD (1997) Mechanism of decreased in vitro murine macrophage cytokine release after exposure to carbon dioxide: relevance to laparoscopic surgery. Ann Surg 226:179-190

69. Ryan GB, Grobéty J, Majno G (1973) Mesothelial injury and recovery. Am J Pathol 71:93-112

70. Taskin O, Buhur A, Birincioglu M, Burak F, Atmaca R, Yilmaz I et al (1998) The effects of duration of $\mathrm{CO}_{2}$ insufflation and irrigation on peritoneal microcirculation assessed by free radical scavengers and total glutathion levels during operative laparoscopy. J Am Assoc Gynecol Laparosc 5:129-133

71. Taskin O, Sadik S, Onoglu A, Gokdeniz R, Yilmaz I, Burak F et al (1999) Adhesion formation after microlaparoscopic and laparoscopic ovarian coagulation for polycystic ovary disease. J Am Assoc Gynecol Laparosc 6:159-163
72. Molinas CR, Koninckx PR (2000) Hypoxaemia induced by $\mathrm{CO}_{2}$ or helium pneumoperitoneum is a co-factor in adhesion formation in rabbits. Hum Reprod 15:1758-1763

73. Binda MM, Molinas CR, Mailova K, Koninckx PR (2004) Effect of temperature upon adhesion formation in a laparoscopic mouse model. Hum Reprod 19:2626-2632

74. Binda MM, Molinas CR, Hansen P, Koninckx PR (2006) Effect of desiccation and temperature during laparoscopy on adhesion formation in mice. Fertil Steril 86:166-175

75. Parker MC, Ellis H, Moran BJ, Thompson JN, Wilson MS, Menzies D et al (2001) Postoperative adhesions: ten-year followup of 12,584 patients undergoing lower abdominal surgery. Dis Colon Rectum 44:822-830

76. Ellis H (2004) Medicolegal consequences of adhesions. Hosp Med 65:348-350

77. Ellis H (2001) Medicolegal consequences of postoperative intraabdominal adhesions. J R Soc Med 94:331-332

78. Trew G (2006) Postoperative adhesions and their prevention. Rev Gynaecol Perinat Pract 6:47-56

79. Wiseman D (2003) Adhesions and informed consent: patients awareness of adhesions prior to surgery. In: Proceedings of the 6th International Symposium on Peritoneum (PAX), Amsterdam, The Netherlands, April 2003. PAX Abstracts pp 21:VII(4)

80. Wiseman D (2003) Obtaining informed consent: patient awareness of adhesions. Adhes News Views 4:10-12

81. Pownall M (1999) Tissue damage is commonest cause of surgical negligence suits. BMJ 318:692

82. Swank DJ, Swank-Bordewijk SC, Hop WC, van Erp WF, Janssen IM, Bonjer HJ et al (2003) Laparoscopic adhesiolysis in patients with chronic abdominal pain: a blinded randomised controlled multi-centre trial. Lancet 361:1247-1251

83. van der Krabben AA, Dijkstra FR, Nieuwenhuijzen M, Reijnen MMPJ, Schaapveld M, van Goor H (2000) Morbidity and mortality of inadvertent enterotomy during adhesiotomy. Br J Surg 87:467-471

84. Ferriman A (2000) Laparoscopic surgery: two thirds of injuries initially missed. BMJ 321:788

85. Skene L, Smallwood R (2002) Informed consent: lessons from Australia. BMJ 324:39-41

86. DeWilde RL, Trew G, on behalf of the Expert Adhesions Working Party of the European Society of Gynaecological Endoscopy (ESGE) (2007) Postoperative abdominal adhesions and their prevention in gynaecological surgery. Expert consensus position. Gynecol Surg. DOI 10.1007/s10397-007-0338-x 